Historic, Archive Document

Do not assume content reflects current scientific knowledge, policies, or practices. 



\section{RIEGEL'S 1928 CONTRACT PRICES ON PEPPER SEED}

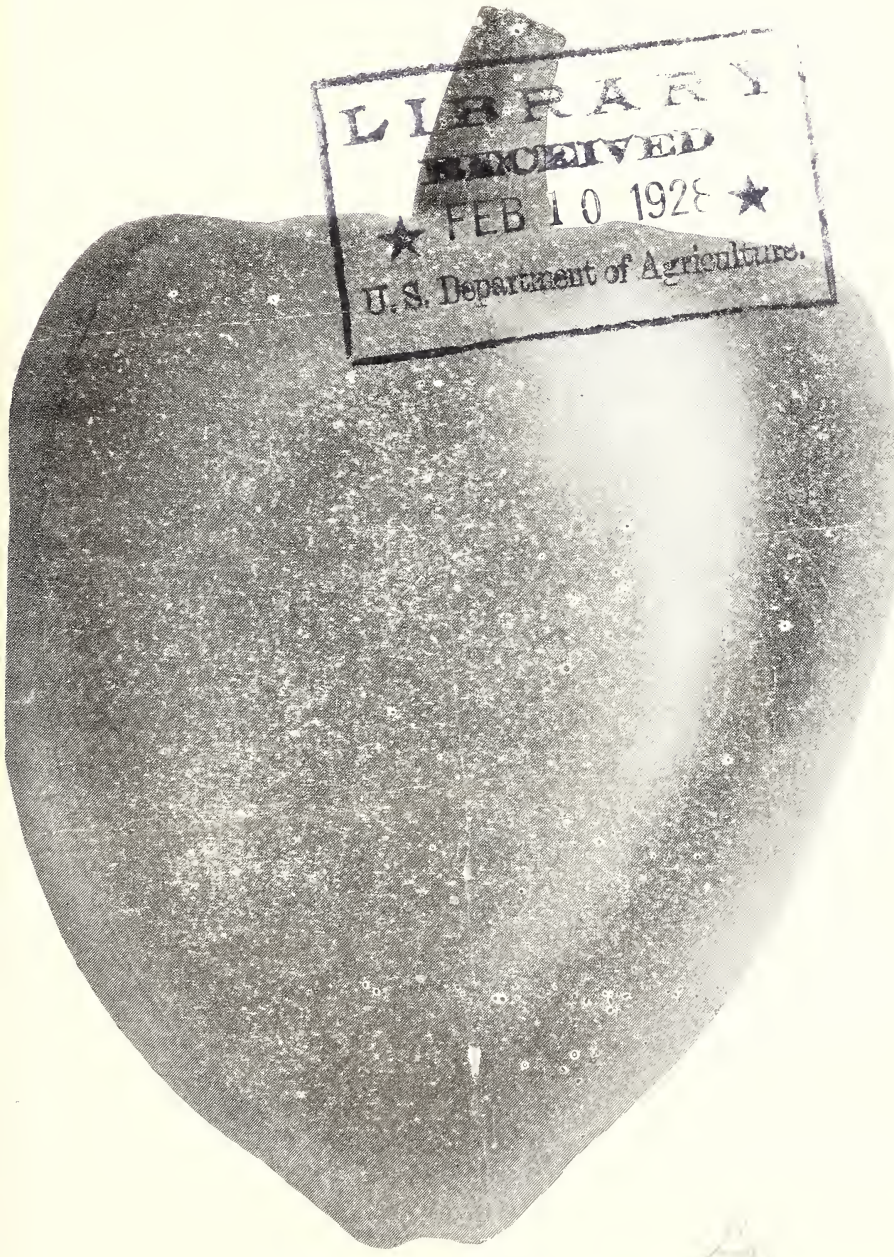




\section{S. D. R!EGEL \& SONS \\ QuALITY PEPPER SEED GROWERS}

To the Seed Trade:-...

In presenting our 1928 price list, we believe that our prices are reasonable considering our well selected strains.

You will notice we are only offering three varieties this time. We have decided to spacialize on these three special padigree strains, which practically cover the three standard types of sweet peppers suited to the different demands.

Purity and perfection will continue to be our great aim in the growing, handling and breeding of these varieties, that they may satisfy every demand for peppers of these types, and that no seedman can afford not to list them.

If we once have your business, we expect to hold it by supplying quality seeds. 


\section{Contract Prices}
$251 \mathrm{lbs}$. and up
Less than 25 lbs.

Royal King

$\$ 1.25$

$\$ 1.50$

Ruby King ......... $1.00 \ldots \ldots \ldots 1.25$

Perfection Pimento ... 1.25 . . . . . . 1.50

Terms: 30 days net, $2 \%$ off for cash 15 days date of invoice.

Seamless bags extra at cost.

S. D. RIEGEL \& SONS,

Experiment, Ga.

Telegraph and Express Office

Griffin, Ga. 


\section{DESCRIPTION}

ROYAL KING-A heavy bearer of large, blocky, smooth, bright, thick meated, uniform peppers. We think much of this pepper. We believe it comes nearer having all the good qualities desired in a pepper of this type than anything on the mariet. As a shipper, it is ideal, because it is the best of keepers, proper shape for packing, smooth and bright. For the home and pickling trade it is perfect-just the right shape and size for stuffing. We are originators and headquarters.

RUBY KING-Our pure strain of this old standard pepper has given wonderful satisfaction. It has proven itself as being extra early, a heavy bearer, large and uniform, flesh sweet and tender, shape good. You will find in our strain the true type. It has proven there is none better.

Perfection Pimento - In a class to itself, and is all that can be desired in a canner's pepper. Very productive, smooth, heart-shaped, enormously thick meated, of proper size, perfectly sweet and deep red. We are originators and headquarters for this great canning pepper. 